\title{
Quantitative detection of iodine in the stratosphere
}

\author{
Theodore K. Koenig $g^{a, b} \oplus$, Sunil Baidar ${ }^{a, b, 1} \oplus$, Pedro Campuzano-Jost ${ }^{a, b} \oplus$, Carlos A. Cuevas ${ }^{c} \oplus$, Barbara Dix ${ }^{a, 2}$,

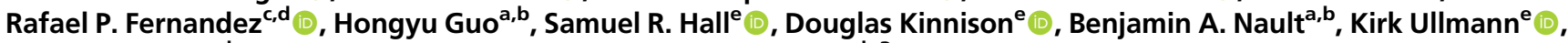 \\ Jose L. Jimenez ${ }^{\mathrm{a}, \mathrm{b}}$, Alfonso Saiz-Lopez ${ }^{\mathrm{C}}\left(\mathbb{0}\right.$, and Rainer Volkamer ${ }^{\mathrm{a}, \mathrm{b}, 3}{ }^{-1(0)}$
}

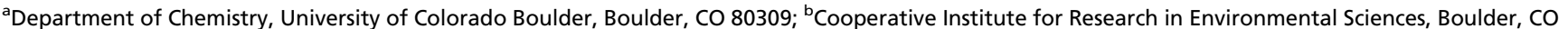
80309; 'Department of Atmospheric Chemistry and Climate, Institute of Physical Chemistry Rocasolano, Spanish National Research Council, 28006 Madrid, Spain; 'Institute for Interdisciplinary Science (ICB), School of Natural Sciences (FCEN), National University of Cuyo (UNCUYO) and National Research Council (CONICET), Mendoza 5501, Argentina; and ${ }^{\mathrm{e} A t m o s p h e r i c ~ C h e m i s t r y ~ O b s e r v a t i o n s ~ a n d ~ M o d e l i n g ~ L a b o r a t o r y, ~ N a t i o n a l ~ C e n t e r ~ f o r ~ A t m o s p h e r i c ~ R e s e a r c h, ~}$
\end{abstract} Boulder, CO 80301

Edited by Mark H. Thiemens, University of California San Diego, La Jolla, CA, and approved December 12, 2019 (received for review September 26, 2019)

Oceanic emissions of iodine destroy ozone, modify oxidative capacity, and can form new particles in the troposphere. However, the impact of iodine in the stratosphere is highly uncertain due to the lack of previous quantitative measurements. Here, we report quantitative measurements of iodine monoxide radicals and particulate iodine $\left(I_{y, p a r t}\right)$ from aircraft in the stratosphere. These measurements support that $0.77 \pm 0.10$ parts per trillion by volume (pptv) total inorganic iodine $\left(\mathrm{I}_{\mathrm{y}}\right)$ is injected to the stratosphere. These high $\mathrm{I}_{\mathrm{y}}$ amounts are indicative of active iodine recycling on ice in the upper troposphere (UT), support the upper end of recent $I_{y}$ estimates ( 0 to $0.8 \mathrm{pptv}$ ) by the World Meteorological Organization, and are incompatible with zero stratospheric iodine injection. Gasphase iodine $\left(I_{y, g a s}\right)$ in the UT $\left(0.67 \pm 0.09\right.$ pptv) converts to $I_{y, p a r t}$ sharply near the tropopause. In the stratosphere, 10 radicals remain detectable $\left(0.06 \pm 0.03\right.$ pptv), indicating persistent $I_{y, p a r t}$ recycling back to $\mathrm{I}_{\mathrm{y}, \mathrm{gas}}$ as a result of active multiphase chemistry. At the observed levels, iodine is responsible for $32 \%$ of the halogen-induced ozone loss (bromine $40 \%$, chlorine $28 \%$ ), due primarily to previously unconsidered heterogeneous chemistry. Anthropogenic (pollution) ozone has increased iodine emissions since preindustrial times (ca. factor of 3 since 1950) and could be partly responsible for the continued decrease of ozone in the lower stratosphere. Increasing iodine emissions have implications for ozone radiative forcing and possibly new particle formation near the tropopause.

iodine | UTLS | stratospheric ozone | gas phase | heterogeneous chemistry

odine participates in catalytic reaction cycles that destroy tropospheric ozone (1-5) and can form new particles $(6,7)$ that modify clouds and Earth albedo. Iodine is widespread throughout the troposphere $(3,8)$, where it contributes up to $30 \%$ to the ozone destruction in the marine boundary layer and upper troposphere (UT) $(4,9)$, reduces the tropospheric ozone burden by $9 \%(4,5)$, modifies oxidative capacity (via $\mathrm{OH}$ radicals), and leads to a net lengthening of the methane lifetime (10). The tropospheric ozone radiative forcing $\left(\mathrm{RF}_{\mathrm{TO} 3}=0.43 \mathrm{~W} \cdot \mathrm{m}^{-2}\right)$ is reduced by $0.087 \mathrm{~W} \cdot \mathrm{m}^{-2}$ due to anthropogenic halogen feedbacks. This change in $\mathrm{RF}_{\mathrm{TO} 3}$ due to bromine and iodine (11) is particularly large in the UT (12) and is larger than the overall stratospheric ozone radiative forcing $\left(0.05 \mathrm{~W} \cdot \mathrm{m}^{-2}\right)(13)$. In the stratosphere, iodine's role is much more uncertain due to the lack of quantitative measurements $(14,15)$.

Previous measurements provide low upper limits, of $<0.1 \mathrm{pptv}$, for iodine monoxide radicals (IO) in the stratosphere from twilight measurements on the ground (16) and from balloons (1719). Recently, IO has been detected in the daytime tropical transition layer (TTL) over the Eastern Pacific Ocean (EPO) (8), implying 0.25 to 0.70 pptv total gas-phase iodine $\left(\mathrm{I}_{\mathrm{y}}=\mathrm{I}+\mathrm{IO}+\right.$ $\mathrm{OIO}+\mathrm{HI}+\mathrm{HOI}+\mathrm{INO}+\mathrm{INO}_{2}+\mathrm{IONO}_{2}+2 \times \mathrm{I}_{2}+\mathrm{ICl}+\mathrm{IBr}+$ $2 \times \mathrm{I}_{2} \mathrm{O}_{2}+2 \times \mathrm{I}_{2} \mathrm{O}_{3}+2 \times \mathrm{I}_{2} \mathrm{O}_{4}$ ), which could be responsible for up to $30 \%$ ozone loss in the tropical lower stratosphere (LS) (20). These $I_{y}$ amounts are expected to include 0.15 to $0.45 \mathrm{pptv}$ IO in the daytime stratosphere, which is well above the upper limits measured at twilight (16-19). Daytime IO (solar zenith angle, $<70^{\circ}$ ) is about $50 \%$ higher and less variable than IO at twilight (for given $\mathrm{I}_{\mathrm{y}, \text { gas }}$; SI Appendix, Fig. S1), owing to the faster photolysis of reservoir species during the day. However, despite these advantages, no systematic attempt has as yet been undertaken to detect daytime IO in the stratosphere. Iodine has also been detected in particles near the tropopause $(21,22)$. However, quantitative measurements of particulate iodine $\left(\mathrm{I}_{\mathrm{y}, \mathrm{part}}\right)$ have not yet been reported. Due to a lack of quantitative evidence, the amounts of iodine injected into the stratosphere are highly uncertain [0 to 0.8 pptv $\left.\mathrm{I}_{\mathrm{y}}(15)\right]$. Indeed, iodine could be irrelevant in the stratosphere, or a major contributor to stratospheric ozone destruction.

\section{lodine in the Upper Troposphere-Lower Stratosphere}

Fig. 1 illustrates the global presence of iodine found during our recent aircraft measurements in the upper troposphere-lower stratosphere (UTLS). IO was measured by the University of Colorado airborne multiaxis-differential optical absorption spectroscopy

\section{Significance}

Aircraft measurements in the lower stratosphere indicate iodine is efficient at destroying ozone in the gas and particulate phases. Active iodine chemistry in the upper tropospherelower stratosphere (UTLS) is the result of convective transport, and efficient multiphase reactions on ice and stratospheric aerosol. Our measurements provide guidance for future technological innovation, laboratory experiments, field observations, and model developments. Global models that simulate the recovery of the ozone layer do not currently consider iodine chemistry. Marine emissions of iodine have increased due to increasing surface ozone in recent decades. This human-induced and increasing iodine source from oceans propagates to the UTLS. Our results posit a possible link between surface air quality, stratospheric ozone loss, and radiative forcing in the UTLS.

Author contributions: R.V. designed research; T.K.K., S.B., P.C.-J., B.D., H.G., S.R.H., B.A.N., K.U., J.L.J., and R.V. performed research; T.K.K., C.A.C., R.P.F., D.K., and A.S.-L. contributed new reagents/analytic tools; T.K.K., P.C.-J., B.D., H.G., B.A.N., J.L.J., and R.V. analyzed data; and T.K.K. and R.V. wrote the paper with contributions from all authors.

The authors declare no competing interest.

This article is a PNAS Direct Submission.

Published under the PNAS license.

Data deposition: CONTRAST IO data are available at https://data.eol.ucar.edu/dataset/383. 023. Particulate iodine data from ATom are available at https://doi.org/10.17605/OSF.IO/ VR6NB. CAM-Chem model data are available at https://saco.csic.es/index.php/s/ 6BKS3PLHYWBKH4g.

${ }^{1}$ Present address: Chemical Sciences Division, National Oceanic and Atmospheric Administration, Boulder, CO 80305.

${ }^{2}$ Present address: Cooperative Institute for Research in Environmental Sciences, Boulder, CO 80309.

${ }^{3}$ To whom correspondence may be addressed. Email: rainer.volkamer@colorado.edu.

This article contains supporting information online at https://www.pnas.org/lookup/suppl/ doi:10.1073/pnas.1916828117/-/DCSupplemental. 
(CU AMAX-DOAS) instrument during the Tropical Ocean Troposphere Exchange of Reactive Halogen Species and Oxygenated VOC (TORERO) (8) and Convective Transport of Active Species in the Tropics (CONTRAST) $(23,24)$ aircraft campaigns (SI Appendix, Table S1). The unique-specific IO fingerprint absorption at blue wavelengths is shown as spectral proof of IO detection over the Western Pacific Ocean (WPO) in the UT (Fig. $1 B, 0.09 \pm 0.03$ pptv) and LS (Fig. 1A, $0.05 \pm 0.03$ pptv). The retrieved IO mixing ratio in the UT is consistent with previous observations in the TTL over the $\operatorname{EPO}(8,25)$. In the LS, daytime IO remains detectable but is found to be three to nine times lower than expected if $\mathrm{I}_{\mathrm{y} \text {,gas }}$ were conserved from the TTL $(8,20)$, consistent with the previously measured upper limits at twilight (16-19). $\mathrm{I}_{\mathrm{y}, \text { part }}$ was measured by the CU high-resolution time-of-flight aerosol mass spectrometer (CU HR-AMS) during the Atmospheric Tomography Mission-1 (ATom-1) and ATom-2 missions $(26,27)$. In contrast to $\mathrm{IO}, \mathrm{I}_{\mathrm{y}, \text { part }}$ signals increase from the UT into the LS. There are no previous quantitative measurements of IO and $\mathrm{I}_{\mathrm{y}, \text { part }}$ in the LS.

The observed decrease in gas-phase iodine in the LS is even more pronounced once the partitioning among inorganic species is considered. This is illustrated in Fig. 2 for a case study from one CONTRAST flight that crossed the subtropical jet stream from the tropical UT into the midlatitude LS of the northern hemisphere (28). Limb measurements taken near local solar noon are particularly sensitive to IO near aircraft altitude (SI Appendix, Tables S2 and S3 and Figs. S2 and S3). The observed IO slightly decreases across the subtropical jet in the LS. However, upon entering the stratospheric overworld (potential temperature, $\theta>380 \mathrm{~K}$ ), IO persists at a stratospheric mixing ratio of $0.06 \pm 0.03$ pptv even in $\sim 10$-y-old stratospheric air. The lower panels in Fig. 2 illustrate the partitioning of $\mathrm{I}_{\mathrm{y} \text {,gas }}$ in the chemical box model based on known chemistry, and how it changes from the UT into the LS during daytime. In the UT, $\mathrm{I}_{\mathrm{y}, \text { gas }}$ is mostly atomic I (74\%) (29), with minor contributions from IO (19\%) and HOI (7\%), while IO in the LS reflects $\sim 60 \%$ of $\mathrm{I}_{\mathrm{y}, \text { gas }}$. This change in $\mathrm{I}_{\mathrm{y}}$, gas partitioning is responsible for an even sharper decrease in $\mathrm{I}_{\mathrm{y}}$,gas than in IO from the tropical UT into the midlatitude LS. Interestingly, we find an excellent correlation between $\mathrm{I}_{\mathrm{y} \text {,gas }}$ and the $\mathrm{H}_{2} \mathrm{O} / \mathrm{O}_{3}$ stratospheric proxy $\left[\mathrm{I}_{\mathrm{y}, \mathrm{gas}}=(0.67 \pm 0.04) \mathrm{pptv}-(0.63 \pm 0.04) \mathrm{pptv} \times\right.$ $\exp \left(-(9.3 \pm 1.8) \times\left(\mathrm{H}_{2} \mathrm{O} / \mathrm{O}_{3}\right)\right) ; P<0.01 \% ;$ SI Appendix, Fig. S4] In contrast to the observations, global model predictions based on tropospheric measurements suggest that $I_{y}$ is essentially independent of altitude across the tropopause (Fig. 3), suggesting that the iodine budget in the UTLS is not closed if considering only gas-phase species.

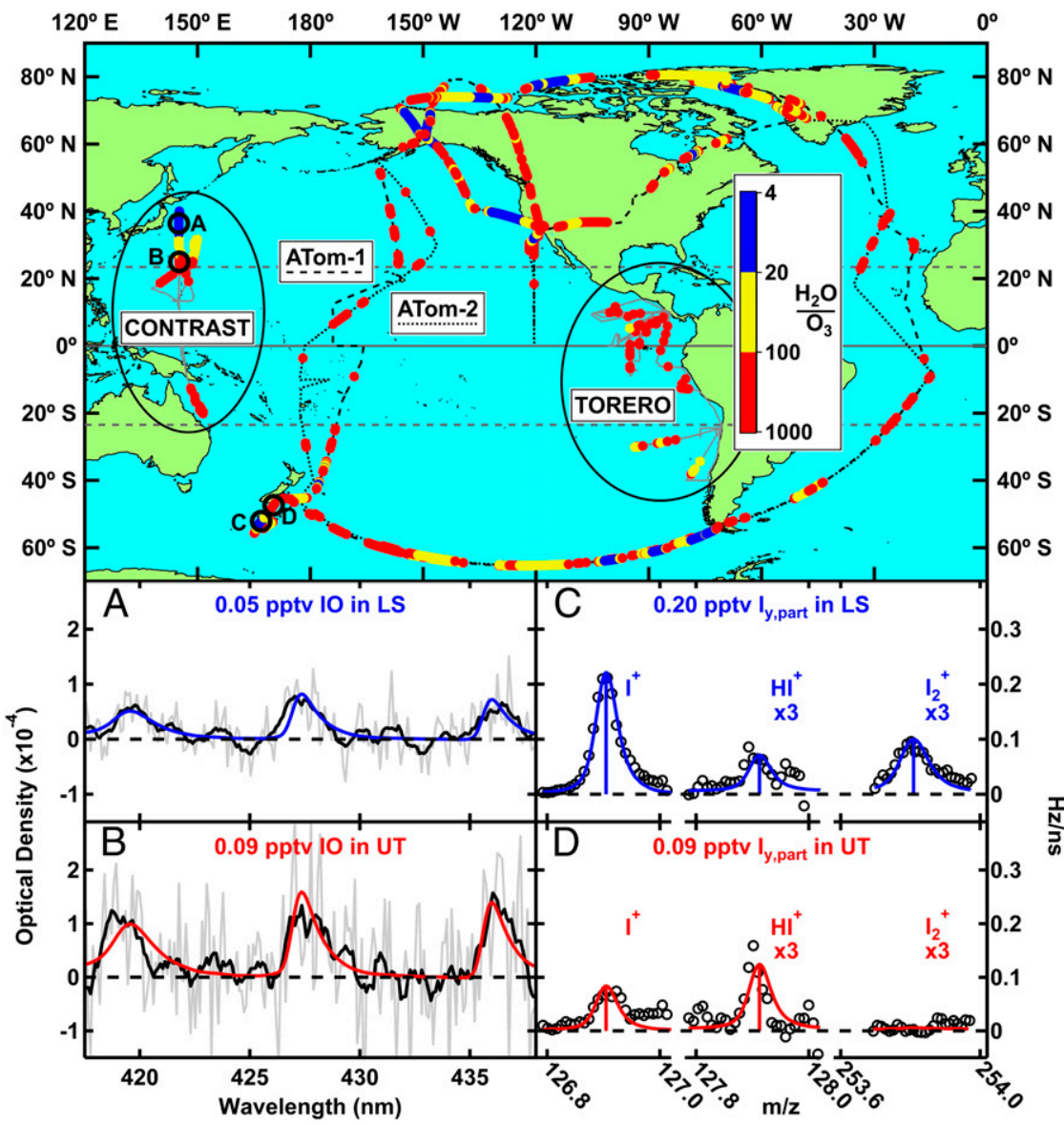

Fig. 1. Overview of iodine measurements in the UTLS. (Top) The CU AMAX-DOAS aboard the NSF/NCAR GV measured IO during TORERO (January to February 2012) and CONTRAST (January to February 2014); the CU HR-AMS measured Iy,part during ATom-1 (July to August 2016) and ATom-2 (January to February 2017). Lower values of the $\mathrm{H}_{2} \mathrm{O} / \mathrm{O}_{3}$ ratio indicate stratospheric air (blue), while higher values (red) are tropospheric; (yellow) intermediate air. $A-D$ refer to locations of measurements on the map. ( $A$ and $B$ ) Spectral proof of 10 absorption, showing the scaled IO reference spectrum (red, blue), overlaying the residual noise (gray, unsmoothed; black, single-pass triangular smoothing to help guide the eye; fit results are indistinguishable for the gray and black lines). ( $C$ and $D$ ) Mass spectral proof of iodine measurements (black) and fitted ion signals (red, blue) in particles; the vertical bars show the ion exact mass. Increasing $\mathrm{HI}^{+}$relative to $\mathrm{I}^{+}$is indicative of iodide, and $\mathrm{I}_{2}{ }^{+}$is indicative of iodate, and $\mathrm{I}^{+}$is the dominant HR-AMS ion signal for both oxidation states. 


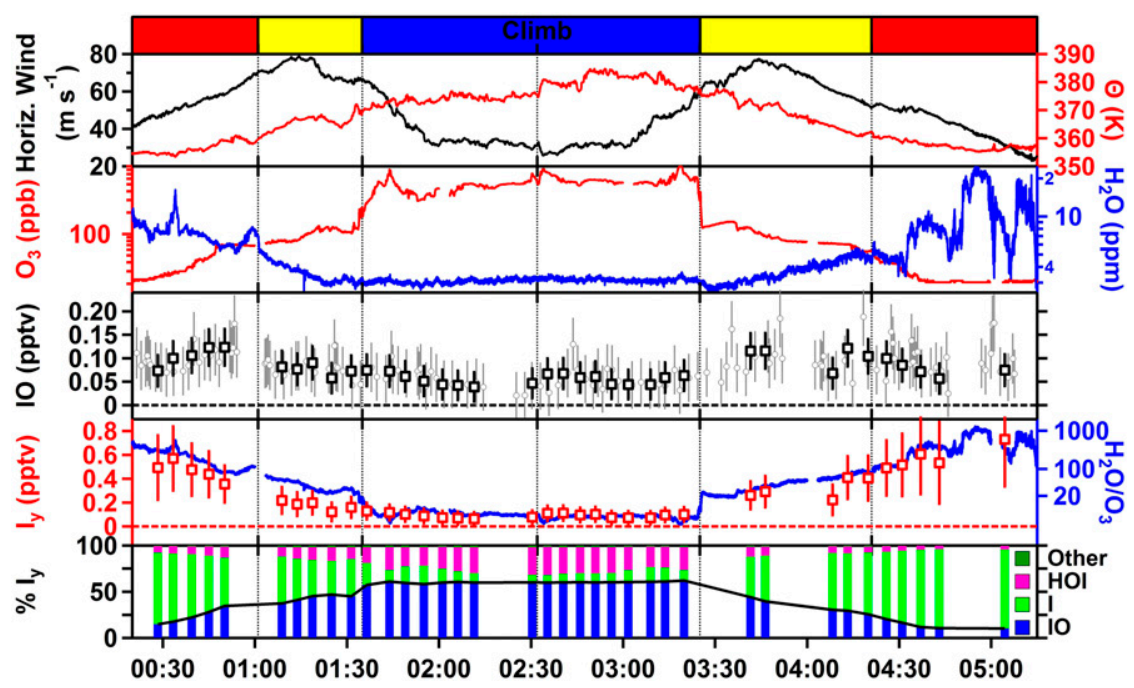

Fig. 2. Gas-phase iodine during CONTRAST RF15 from the tropical UT into the NH midlatitude LS. The top bar is color coded by the $\mathrm{H}_{2} \mathrm{O} / \mathrm{O}_{3}$ ratio as in Fig. 1 . The Top two panels show meteorological and chemical indicators across the subtropical jet. Middle panel: IO mixing ratios measured by the CU AMAX-DOAS every $30 \mathrm{~s}$ (gray), and 5-min average IO (black). Lower two panels: $\mathrm{I}_{\mathrm{y}, \text { gas }}$ (red) is inferred from IO using the $\mathrm{IO} / \mathrm{I}_{\mathrm{y}, \text { gas }}$ ratio (black line) using a box model. The $\mathrm{H}_{2} \mathrm{O} / \mathrm{O}_{3}$ ratio (blue) follows the trend in $\mathrm{I}_{\mathrm{y}, \text { gas }}$. The speciation of $\mathrm{I}_{\mathrm{y}, \text { gas }}$ is shown in the lowermost panel. The time axis shows UTC time on February $25,2014$.

\section{Particulate lodide and Reactive Ozone Uptake}

The increase in $\mathrm{I}_{\mathrm{y}, \mathrm{part}}$ from the UT to the LS can be attributed entirely to iodate $\left(\mathrm{IO}_{3}{ }^{-}\right)$formation, as is evidenced from aerosol mass spectra recorded in the UT (Fig. 1D) and LS (Fig. 1C). $\mathrm{I}_{\mathrm{y}, \text { part }}$ is detected by the CU HR-AMS in the form of three major (positive) ions (SI Appendix, Figs. S5 and S6 and Table S4): $\mathrm{I}^{+}$is a major signal from both particle iodide $\left(\mathrm{I}^{-}\right)$and $\mathrm{IO}_{3}{ }^{-}$; the oxidation states can be distinguished, with $\mathrm{HI}^{+}$indicating $\mathrm{I}^{-}$, and $\mathrm{I}_{2}^{+}$indicating $\mathrm{IO}_{3}^{-}$(SI Appendix, Fig. S7 and Table S5). Small but significant $\mathrm{HI}^{+}$signals indicate persistent $\mathrm{I}^{-}$in both the UT and $\mathrm{LS}$, while $\mathrm{I}_{2}{ }^{+}$indicates a marked increase in $\mathrm{IO}_{3}{ }^{-}$in the LS. At midlatitudes, $\mathrm{I}_{\mathrm{y}, \text { gas }}$ and $\mathrm{I}_{\mathrm{y}, \text { part }}$ have opposite exponential dependences on $\mathrm{H}_{2} \mathrm{O} / \mathrm{O}_{3}$ (SI Appendix, Fig. S4 and Eqs. S2 and S3; both $P<0.01 \%)$. We assume based on CAM-Chem that $\mathrm{I}_{\mathrm{y}}$ is conserved across the tropopause (Fig. $3 B$ and SI Appendix, Eqs. S4 and S5); testing of this assumption is possible using existing technology on research aircraft and will require simultaneous measurements of $\mathrm{I}_{\mathrm{y}, \mathrm{gas}}$ and $\mathrm{I}_{\mathrm{y}, \text { part }}$ across the tropopause in the future. Interestingly, the particulate iodide $\left(\mathrm{I}^{-}\right)$mass concentration remains rather

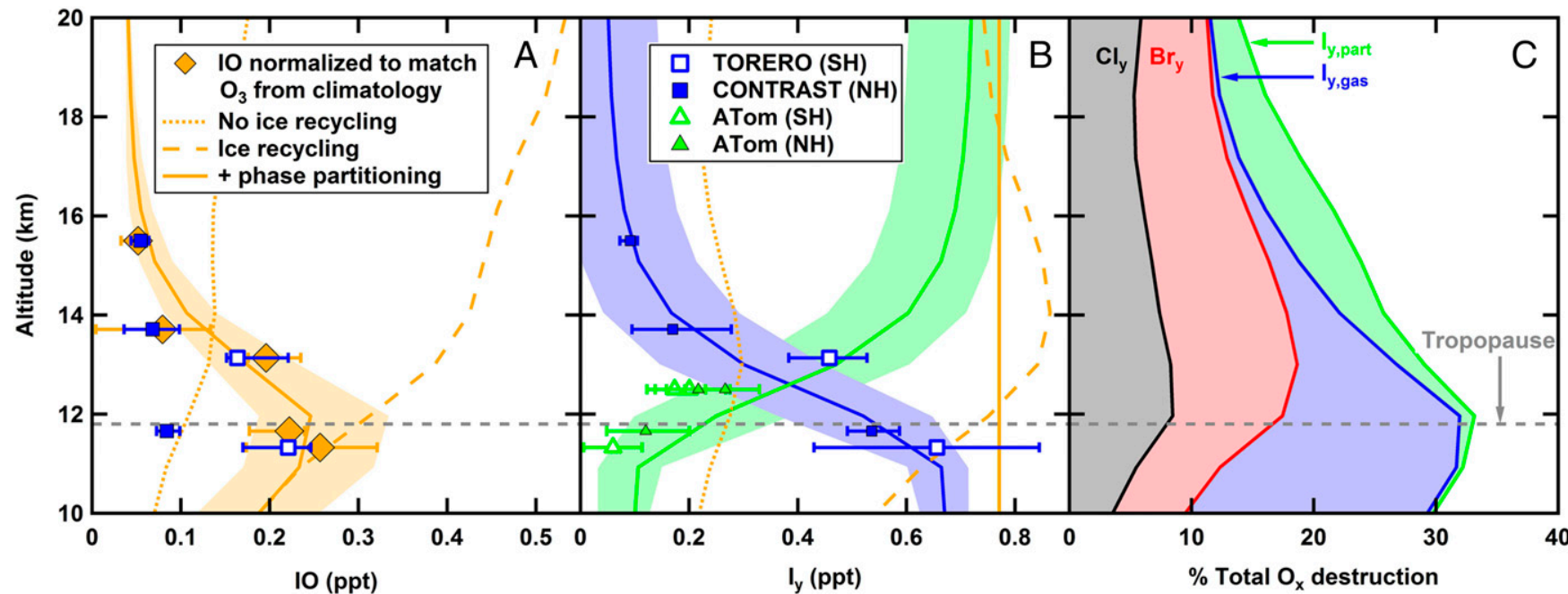

Fig. 3. The iodine budget and odd-oxygen destruction in the UTLS at midlatitudes. Symbols indicate measured data, while all lines and shading are calculations. (A) Comparison of IO, measurements (blue) are adjusted to match chemical partitioning for the zonal ozone climatology (orange). The dashed lines (short and long dashes) are CAM-Chem simulations excluding or including recycling of iodine on ice as indicated (20), and the solid line is based on a constant $\mathrm{I}_{\mathrm{y}}$ of $0.77 \mathrm{pptv}$ and $\mathrm{I}_{\mathrm{y}, \text { gas }}$ determined by an empirical fit against $\mathrm{H}_{2} \mathrm{O} / \mathrm{O}_{3}$ with shading indicating uncertainty in the fit (see SI Appendix, Eq. S2 for details). (B) In orange, total $\mathrm{I}_{\mathrm{y}}$. The dashed lines indicate the same CAM-Chem model cases as in $A$, and the solid line is the assumed constant $\mathrm{I}_{\mathrm{y}}$ in reasonable agreement with the ice-recycling case. $\mathrm{I}_{\mathrm{y} \text {,gas }}$ (blue) based on an empirical against $\mathrm{H}_{2} \mathrm{O} / \mathrm{O}_{3}$ (see S/ Appendix, Eq. S2 for details) dominates in the troposphere and decreases rapidly around the tropopause; $\mathrm{I}_{\mathrm{y}, \text { part }}$ (green) is taken as $\mathrm{I}_{\mathrm{y}, \text { part }}=0.77 \mathrm{pptv}-\mathrm{I}_{\mathrm{y}, \mathrm{gas}}$ (see $S \mathrm{I}$ Appendix, Eq. S5 for details). Markers indicate the measured medians from the indicated mission and hemisphere; error bars indicate the interquartile range. Markers are plotted based on the $\mathrm{H}_{2} \mathrm{O} / \mathrm{O}_{3}$ ratio in the zonal climatology, or at the aircraft ceiling altitude ( $12.5 \mathrm{~km}$ for the DC-8 and $15.5 \mathrm{~km}$ for the GV), whichever is lower. (C) Odd-oxygen destruction by halogen families computed with the CU box model (SI Appendix); the contribution of each family has been added in the following order: chlorine ( $\mathrm{Cl}_{\mathrm{y}}$, black); bromine (Bry, red); gas-phase iodine ( $\mathrm{I}_{\mathrm{y}, \mathrm{gas}}$, blue); and particulate iodine $\left(\mathrm{I}_{\mathrm{y}, \text { part, }}\right.$ green). The dashed gray line is indicative of the location of the tropopause in ATom data. 
Table 1. Reactive uptake due to the $\mathrm{O}_{3}+$ iodide reaction at Northern Hemisphere midlatitudes

\begin{tabular}{lccccccc} 
Altitude, $^{*} \mathrm{~km}$ & $\mathrm{H}_{2} \mathrm{O} / \mathrm{O}_{3}$ & $\mathrm{I}_{\mathrm{y}, \text { gas, }}$ pptv & $\mathrm{I}_{\mathrm{y}, \text { part, }} \mathrm{pptv}$ & $\mathrm{I}^{-}, \mathrm{pptv}^{\dagger}$ & $\mathrm{I}^{-} / \mathrm{I}_{\mathrm{y}, \text { part, }} \%^{\dagger}$ & {$\left[\mathrm{I}^{-}\right], \mathrm{mmol} / \mathrm{kg}^{\ddagger}$} & $\gamma_{\mathrm{O}+\text { iodide, }}{ }^{\ddagger \S} \times 10^{-6}$ \\
\hline $14.7-17.7$ & $20-4$ & 0.08 & 0.70 & $0.09(0.05,0.13)$ & $13(7,19)$ & $14 .(3.4,41)$ & $7.0(1.9,15)$. \\
$12.8-14.7$ & $100-20$ & 0.25 & 0.52 & $0.09(0.05,0.13)$ & $17(10,25)$ & $7.3(2.2,15)$. & $4.0(0.9,8.7)$ \\
$10.6-12.8$ & $1,000-100$ & 0.56 & 0.21 & $0.09(0.05,0.13)$ & $44(24,63)$ & $59(5.1,190)$ & $17 .(2.3,40)$. \\
\hline
\end{tabular}

Unless otherwise noted, reported values are arithmetic means.

*This altitude range corresponds to the CAM-Chem zonal climatology range of $\mathrm{H}_{2} \mathrm{O} / \mathrm{O}_{3}$ ratios.

${ }^{\dagger}$ The values reported in parentheses for the $\mathrm{I}^{-}$mixing ratio and fraction of $\mathrm{I}_{\mathrm{y} \text {,part }}$ reflect the uncertainty in the determination of the mean; see SI Appendix for details.

${ }^{\ddagger}$ Values reported in parentheses reflect uncertainty in $\mathrm{I}^{-}$as well as atmospheric variability. Low values in parentheses are the lowest value obtained for any 5-min average during CONTRAST assuming the smaller amounts of $\mathrm{I}^{-}$; high values are the highest value obtained for any 5-min average assuming the larger amounts of $\mathrm{I}^{-}$.

${ }^{\S} \gamma_{03+i o d i d e}$ is the reactive uptake coefficient for ozone reactions with particulate iodine. For conditions in the UTLS $\gamma_{03+i o d i d e}$ is equal to the bulk reaction resistance $\Gamma_{\mathrm{b}}$; see $S I$ Appendix for details. Uncertainties in input parameters can lead to systematic changes in the value of $\gamma_{03+i o d i d e}$ by many orders of magnitude; this is not reflected here.

constant across the tropopause (SI Appendix). The result is a decreasing $\mathrm{I}^{-} / \mathrm{I}_{\mathrm{y}, \text { part }}$ ratio in the LS (Table 1), due to a shift in iodine partitioning toward $\mathrm{IO}_{3}{ }^{-}$.

Halogen-induced ozone destruction in the LS does not currently consider reactive ozone uptake due to heterogeneous reactions $(14,15)$. However, the reaction of ozone with particulate $\mathrm{I}^{-}$proceeds at a rate that is over a million times faster than for other halides (30-32). We use the atmospheric conditions measured during CONTRAST to examine the relevance of $0.09 \mathrm{pptv}$ of $\mathrm{I}^{-}$in the UTLS in terms of the reactive uptake coefficient, $\gamma_{\text {O3+iodide }}$ (SI Appendix). No extrapolation of $\mathrm{I}_{\mathrm{y} \text {,part }}$ data across the tropopause enters our analysis. Table 1 and SI Appendix, Fig. S8 are based on $\mathrm{I}^{-}$measurements in the LS and show that $\gamma_{\mathrm{O} 3+\text { iodide }}$ varies by about a factor of 2 between the UT and LS. They support a value for $\gamma_{\mathrm{O} 3+\text { iodide }}$ of $7.0 \times 10^{-6}$ in the LS (SI Appendix), suggesting reactive uptake is an important ozone loss mechanism that should not be ignored.

\section{lodine Injection to the Stratosphere}

Our measurements suggest a total of $0.77 \pm 0.10$ pptv total $\mathrm{I}_{\mathrm{y}}$ (87\% gas, $13 \%$ particle in the UT) are injected into the stratosphere (SI Appendix). Fig. $3 A$ compares IO measurements from both TORERO and CONTRAST with the CAM-Chem model (20), which treats only gas-phase iodine. For comparison of the two datasets with the model, gas-phase iodine partitioning has been normalized to the observed zonal ozone climatology here (orange diamonds). As can be seen, the 0.23 pptv IO in the UT are only compatible with the simulation that includes iodine recycling on ice surfaces in the model. In absence of ice recycling, iodine washout is more efficient and leads to lower $\mathrm{I}_{\mathrm{y}}$ in the UT that is incompatible with the IO observations. This evidence for ice recycling further corroborates active multiphase $\mathrm{I}_{\mathrm{y}}$ chemistry.

Furthermore, the decreasing but significant daytime IO in the LS is 8.4 times smaller than the IO expected from the icerecycling case in CAM-Chem, and 2.6 times smaller than the nonrecycling case. The model overestimates $\mathrm{I}_{\mathrm{y} \text {,gas }}$ by similar factors in Fig. $3 B$. Most notably, the observed $\mathrm{I}_{\mathrm{y}}$ vertical profile can only be reproduced if multiphase iodine partitioning is considered; i.e., assuming total $\mathrm{I}_{\mathrm{y}}$ is conserved across the tropopause and that $\mathrm{I}_{\mathrm{y}, \mathrm{gas}}$ and $\mathrm{I}_{\mathrm{y}, \text { part }}$ follow the stratospheric $\mathrm{H}_{2} \mathrm{O}$ / $\mathrm{O}_{3}$ correlation (SI Appendix, Eqs. S2 and S5). The ice-recycling case that well approximates $\mathrm{I}_{\mathrm{y}}$ in the UT is thus only compatible with the $I_{y, g a s}$ observations in the LS if phase partitioning of iodine to particles is considered.

The persistence of $\mathrm{I}_{\mathrm{y}, \text { gas }}$, signified by $\mathrm{IO}$, and of $\mathrm{I}^{-}$in particles is indicative of active chemical recycling of iodine between the gas and particle phases in both the UT and LS. The heterogeneous $\mathrm{I}^{-}+\mathrm{O}_{3}$ reaction is known to recycle $\mathrm{I}^{-}$to $\mathrm{I}_{\mathrm{y} \text {,gas }}(32,33)$. Moreover, condensed-phase iodine undergoes well-established chemical oscillation reactions [e.g., the Dushman (34) reaction, and the Bray-
Liebhafsky (35) mechanism] that comproportionate $\mathrm{I}^{-}$and $\mathrm{IO}_{3}{ }^{-}$to $\mathrm{HOI}$ and $\mathrm{I}_{2}$, which can volatilize. However, the persistence of $\mathrm{I}_{\mathrm{y}, \mathrm{gas}}$ in aged stratospheric air suggests that chemical oscillator reactions aid iodine recycling from atmospheric particles and sustain ozone destruction in both phases into the stratospheric overworld.

\section{Efficiency of lodine and Other Halogens at Destroying Ozone}

Iodine has previously been estimated to have 600 times the ozone destruction potential of chlorine in the LS (14). The efficiency at which $\mathrm{I}_{\mathrm{y}, \mathrm{gas}}$ and $\mathrm{I}_{\mathrm{y} \text {,part }}$ destroy odd oxygen is calculated as the rate of odd-oxygen destruction divided by the $\mathrm{I}_{\mathrm{y}, \mathrm{gas}}$ and $\mathrm{I}_{\mathrm{y} \text {,part }}$ concentration in Table 2 (SI Appendix). This first-order loss rate is roughly constant for $\mathrm{I}_{\mathrm{y} \text {,gas }}\left(\sim 1.9 \times 10^{-3} \mathrm{~s}^{-1}\right)$ but increases for $\mathrm{I}_{\mathrm{y}, \text { part }}$ in the LS due to an increased frequency of ozone collisions with particles (SI Appendix, Fig. S8 and Table 2). We conclude that, on a per-atom basis, $I_{y, g a s}$ is two to seven times more efficient at destroying ozone in the UTLS than $\mathrm{I}_{\mathrm{y}, \mathrm{part}}$. However, given the shift in iodine partitioning toward $\mathrm{I}_{\mathrm{y}, \mathrm{part}}$, heterogeneous reactions dominate iodine related ozone loss in the LS.

For comparison of ozone destruction from iodine with that from other halogens, we use the relative efficiencies $\chi_{\mathrm{I} \text {,part }}$ and $\chi_{\mathrm{I}, \mathrm{gas}}$ (SI Appendix) to scale the gas-phase iodine-induced ozone destruction in CAM-Chem. $\mathrm{Cl}_{\mathrm{y}}$ and $\mathrm{Br}_{\mathrm{y}}$ are more abundant than $\mathrm{I}_{\mathrm{y}}$ in the UTLS, but their impact on ozone is not correspondingly higher, reflecting the greater efficiency of iodine (Table 2). Previous estimates of $\mathrm{I}_{\mathrm{y}}$ efficiency did not consider $\mathrm{I}_{\mathrm{y}, \text { part }}$, which has a lower efficiency than $\mathrm{I}_{\mathrm{y} \text {,gas }}$ at ozone destruction. The overall mean iodine efficiency with respect to chlorine increases in the LS (both phases), but remains slightly lower than previous estimates (UT, 220; LS, 470). We still conclude that iodine in both phases is more efficient on a per-atom basis at destroying ozone in the LS than bromine (factor 6 to 15) and chlorine (factor 400 to 1,000$)$.

Fig. $3 C$ shows the iodine contribution to ozone loss in the UTLS. While the iodine contribution peaks in the UT, it persists in the LS, where iodine is responsible for an equivalent amount of ozone loss as chlorine and bromine. Overall halogens are responsible for $22 \%$ loss in the LS (iodine, $7.0 \%$; bromine, $8.8 \%$; chlorine, $6.3 \%$ ), second only to $\mathrm{HO}_{\mathrm{x}}(68 \%)$, with minor contributions from $\mathrm{NO}_{\mathrm{x}}(7 \%)$ and $\mathrm{O}_{\mathrm{x}}(3 \%)$. The percent numbers in Table 2 refer to fractions of the halogen contribution here. Both $\mathrm{I}_{\mathrm{y} \text {,gas }}$ and $\mathrm{I}_{\mathrm{y} \text {,part }}$ make significant contributions in the LS, with potential to increase in the future.

\section{Recent Field Observations and Uncertainties}

While the most recent WMO ozone assessment (15) has considered the likelihood of greater $\mathrm{I}_{\mathrm{y}}$ injection into the stratosphere, the potential impact of injected $\mathrm{I}_{\mathrm{y}}$ on stratospheric ozone was last quantitatively assessed more than a decade ago (36). The impact 
Table 2. Comparison of iodine, bromine, and chlorine efficiencies at destroying ozone in the UTLS

\begin{tabular}{|c|c|c|c|c|c|}
\hline Halogen & $X_{y}$, pptv* & $d \mathrm{O}_{x} / d t, \times 10^{3} \mathrm{molec} \cdot \mathrm{cm}^{3} \cdot \mathrm{s}^{-1}{ }_{*}{ }^{\dagger}$ & $\chi_{\mathrm{X}, \mathrm{a}}{ }^{\ddagger} \mathrm{s}^{-1}$ & $\chi_{\mathrm{x}, \mathrm{a}} / \chi_{\mathrm{Cl}}{ }^{\S}$ & $\% \mathrm{O}_{\mathrm{x}}$ destruction \\
\hline \multicolumn{6}{|c|}{ Lower stratosphere } \\
\hline Chlorine & 325.5 & 2.26 & $1.98 \times 10^{-6}$ & 1 & 28 \\
\hline Bromine & 6.35 & 3.17 & $1.35 \times 10^{-4}$ & 69.8 & 40 \\
\hline lodine & 0.77 & 2.52 & $8.8 \times 10^{-4}$ & 470 & 32 \\
\hline Gas & 0.11 & 0.78 & $1.9 \times 10^{-3}$ & 980 & 10. \\
\hline Particle & 0.67 & 1.74 & $7.2 \times 10^{-4}$ & 390 & 22 \\
\hline \multicolumn{6}{|c|}{ Upper troposphere } \\
\hline Chlorine & 94.2 & 3.19 & $6.02 \times 10^{-6}$ & 1 & 23 \\
\hline Bromine & 2.77 & 3.76 & $2.21 \times 10^{-4}$ & 38.5 & 27 \\
\hline lodine & 0.77 & 6.88 & $1.3 \times 10^{-3}$ & 220 & 50 \\
\hline Gas & 0.50 & 6.34 & $1.9 \times 10^{-3}$ & 340 & 46 \\
\hline Particle & 0.28 & 0.55 & $3.2 \times 10^{-4}$ & 59 & 4.0 \\
\hline
\end{tabular}

Reported values are computed for the average of the midlatitude zonal means ( $20^{\circ}$ to $60^{\circ}$ latitude for both hemispheres). *Mixing ratios of chlorine and bromine are taken directly from CAM-Chem. Values for iodine are based on SI Appendix, Eqs. S2 and S5.

${ }^{\dagger}$ The ozone destruction rates are taken from CAM-Chem. The ozone destruction of $I_{y}$,part is adjusted based on the relative efficiency compared to $\mathrm{I}_{\mathrm{y}, \mathrm{gas}}$ (SI Appendix, Eq. S8).

${ }^{\ddagger} \chi_{\mathrm{X}, \mathrm{a}}=\left(d \mathrm{O}_{\mathrm{x}} / d t\right) / \mathrm{X}_{\mathrm{y}, \mathrm{a}}$ is the efficiency to destroy ozone per $\mathrm{X}_{\mathrm{a}}$ atom $(\mathrm{X}=\mathrm{Cl}, \mathrm{Br}$, l; subscript "a" = "gas" or "particle").

${ }^{\S} \chi_{\mathrm{X}, \mathrm{a}} / \chi_{\mathrm{Cl}}$ is the efficiency relative to chlorine.

"The fraction of halogen-induced ozone destruction.

of 0.1 pptv $\mathrm{I}_{\mathrm{y}}$ (the upper limit for total iodine at the time) is consistent with the $2.2 \%$ of ozone loss from 0.11 pptv $\mathrm{I}_{\mathrm{y} \text {,gas }}$ in the LS. The 0.67 ppt $\mathrm{I}_{\mathrm{y}, \mathrm{part}}$ are found to be responsible for an additional $4.9 \%$ ozone loss. Coincidentally, the total impact from iodine $(7 \%)$ is close to a prior estimate based on upper limits that neglects the temperature dependence of kinetics (36).

Recent analysis of trends in $30 \mathrm{y}$ of ozone profile measurements reveal a continued decrease in the LS and emphasize the lack of an anticipated recovery of LS ozone under the Montreal Protocol. Ball et al. (37) have concluded that "the reasons for the continued reduction of lower stratospheric ozone are not clear; models do not reproduce these trends, and thus the causes now urgently need to be established." It is noteworthy that most climate models currently do not include iodine chemistry. In our simulations, excluding iodine chemistry results in an increase in the ozone column of $2.61 \mathrm{DU}(2.2 \%)$ in the midlatitude LS (147 to $32 \mathrm{hPa} ; 13$ to $24 \mathrm{~km})$ and smaller changes higher in the stratosphere $(<0.3 \mathrm{DU})$. This effect of iodine is in principle of a similar magnitude as the gap between observed and predicted ozone trends in the LS at midlatitudes. For iodine to contribute to a decreasing ozone trend iodine emissions would need to increase over time, which is supported by recent ice core $(38,39)$ and tree ring (40) records.

The above estimates of iodine impacts on the ozone column assume all iodine behaves as gas-phase iodine. Notably, there are significant uncertainties in the efficiency of multiphase chemistry at destroying ozone. Our calculations of $\gamma_{\mathrm{O} 3+\text { iodide }}$ in Table 1 rely on existing laboratory measurements of the $\mathrm{O}_{3}+\mathrm{I}^{-}$reaction rate constant (30) near room temperature. In particular, the temperature dependence of the reaction rate constant has been measured between 275 and $293 \mathrm{~K}$, and estimates of its value in the UTLS rely on an activation energy $\left(E_{\mathrm{a}}=73 \pm 29 \mathrm{~kJ} \cdot \mathrm{mol}^{-1}\right)$ that is known to within $40 \%$ (30). Furthermore, the temperature dependence of ozone solubility has been measured in aqueous solutions above $273 \mathrm{~K}(41)$, and extrapolation to colder temperatures is compensated by Setschenow salting effects in sulfuric acid $(42,43)$; both effects have similar magnitudes (approximately two orders of magnitude), but opposite signs. It is currently unclear whether the impact of colder temperatures increases or decreases $\gamma_{\mathrm{O} 3+\text { iodide }}$ over the values given in Table 1 .

Future laboratory measurements are needed of the temperaturedependent reaction rate coefficient of $\mathrm{I}^{-}+\mathrm{O}_{3}$, the ozone solubility in sulfuric acid aerosol, and the drivers of redox equilibria that couple $\mathrm{I}^{-}$(oxidation state, $\mathrm{OS}=-1$ ), $\mathrm{HOI}(\mathrm{OS}=+1)$, and $\mathrm{IO}_{3}{ }^{-}$ $(\mathrm{OS}=+5)$. The reduction of $\mathrm{IO}_{3}{ }^{-}$is well studied $(34,44,45)$, but its mechanism remains elusive (46), and it has been neglected in atmospheric models (47). Furthermore, iodine redox chemistry in highly concentrated sulfuric acid is highly sensitive to small amounts of water (48), which is generally consistent with the observed trends. The efficiencies of multiphase chemical reactions of iodine could increase or decrease the estimates of the impact iodine has on the ozone column and trends in the LS. There is currently no global or climate model that represents condensedphase iodine chemistry in part due to these uncertainties. In order to constrain a larger portion of $\mathrm{I}_{\mathrm{y}}$ injected to the stratosphere, future field observations are needed that simultaneously measure $I_{y, g a s}$ and $I_{y, p a r t}$ across the tropopause.

\section{lodine in the Anthropocene}

A potential climate relevance arises from the fact that anthropogenic pollution ozone in the troposphere has increased the global iodine source by roughly a factor of 3 since 1950 (38-40). Ozone reacts with $\mathrm{I}^{-}$at the ocean surface, which results in ozone deposition and the emission of HOI and $\mathrm{I}_{2}$ to the atmosphere. This inorganic iodine source dominates the global iodine budget $(4,5)$ and is deemed to have partially buffered increases in tropospheric ozone relative to preindustrial levels (49). We have conducted sensitivity studies using CAM-Chem (Materials and Methods, 50, 51) that show the inorganic iodine source dominates over organic sources (e.g., $\mathrm{CH}_{3} \mathrm{I}$ ) in determining the $\mathrm{I}_{\mathrm{y}}$ burden in the UT in the present day (Fig. 4). Notably, if we turn on the iodine chemistry in CAM-Chem, the change in ozone in the LS due to iodine (2.6 DU) is four to five times larger than that of changing very short-lived substance (VSLS)-bromine and VSLS-chlorine emissions combined over 20 y (52), but occurs over longer timescales. Inorganic iodine sources are expected to increase further in the future as a result of these tropospheric ozone pollution feedbacks. The impact of iodine on LS ozone is expected to increase as a result. The continuation of monitoring the ozone trends in the LS, supplemented by iodine observations, is needed to better attribute the cause of the persistent decline of ozone in the LS indicated by recent field observations (37).

Moreover, iodic acid $\left(\mathrm{HIO}_{3}\right)$ and higher iodine oxides (i.e., $\mathrm{I}_{\mathrm{x}} \mathrm{O}_{\mathrm{y}}$ ) are stabilized at the cold temperatures near the tropopause (53) and may contribute to particle nucleation and growth (7). 


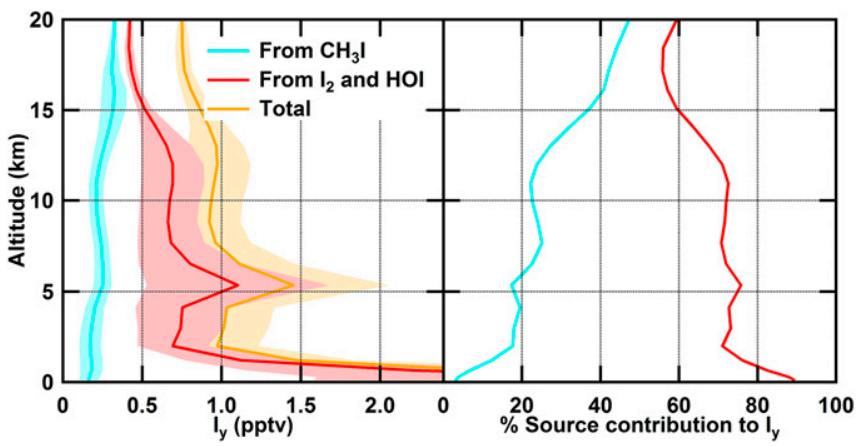

Fig. 4. Contribution of organic $\left(\mathrm{CH}_{3} \mathrm{l}\right)$ and inorganic iodine $\left(\mathrm{I}_{2}+\mathrm{HOI}\right)$ emissions to the $\mathrm{I}_{\mathrm{y}}$ burden of the CAM-Chem model within the Tropics $\left(20^{\circ} \mathrm{N}\right.$ to $\left.20^{\circ} \mathrm{S}\right)$. (Left) $\mathrm{I}_{\mathrm{y}}$ from a simulation including both organic and inorganic emissions of iodine (orange), a simulation including only emissions of $\mathrm{CH}_{3} \mathrm{l}$ (blue), and a simulation including only inorganic iodine emissions (red). (Right) Percentage contribution of $\mathrm{CH}_{3} \mathrm{l}$ (blue) and inorganic emissions (red) to the total iodine burden.

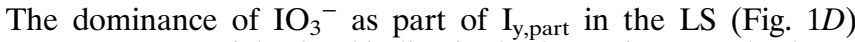
supports a potential role of iodine in the formation/growth of new particles near the tropopause. Furthermore, increasing stratospheric water vapor (54) leads to increasing ozone destruction in the LS via enhanced chlorine recycling (55); the response of multiphase iodine chemistry is expected to be similarly enhanced as dilution of sulfate increases ozone solubility. We hypothesize that this could invigorate ozone loss in the UTLS by releasing iodine from particles. Finally, iodine destroys ozone at those altitudes where $\mathrm{RF}_{\mathrm{TO}}$ is particularly sensitive to changes in ozone (56), and ozone circulation feedbacks affect climate sensitivities (57). These diverse and complex climate feedbacks due to anthropogenically enhanced iodine in the UTLS/tropopause warrant further investigation.

\section{Materials and Methods}

The iodine measurements were collected during four aircraft campaigns: 1) the TORERO field campaign (8), 2) the CONTRAST field campaign (23), 3) the ATom-1, and 4) ATom-2 (26). The ratio $\mathrm{H}_{2} \mathrm{O} / \mathrm{O}_{3}$ was used as a consistent classification metric of air as tropospheric or stratospheric applicable across latitude, season, and field campaign (SI Appendix).

10 radicals were measured by the CU AMAX-DOAS instrument $(3,8,28)$ aboard the National Science Foundation (NSF)/National Center for Atmospheric Research (NCAR) GV aircraft during TORERO and CONTRAST. TORERO conducted 17 research flights (RFs) over the EPO. The aircraft was based out of Antofagasta, Chile, and San Jose, Costa Rica, and flights were conducted in January and February 2012. CONTRAST conducted 17 RFs over the WPO. The aircraft was based out of Guam, and flights were conducted in January and February 2014. $\mathrm{l}_{\mathrm{y} \text {,gas }}$ for CONTRAST and TORERO was inferred from IO measurements using a chemical box model developed at the University

1. B. Alicke, K. Hebestreit, J. Stutz, U. Platt, lodine oxide in the marine boundary layer Nature 397, 572-573 (1999).

2. K. A. Read et al., Extensive halogen-mediated ozone destruction over the tropical Atlantic Ocean. Nature 453, 1232-1235 (2008).

3. B. Dix et al., Detection of iodine monoxide in the tropical free troposphere. Proc. Natl. Acad. Sci. U.S.A. 110, 2035-2040 (2013).

4. A. Saiz-Lopez et al., lodine chemistry in the troposphere and its effect on ozone. Atmos. Chem. Phys. 14, 13119-13143 (2014).

5. T. M. Sherwen et al., lodine's impact on tropospheric oxidants: A global model study in GEOS-chem. Atmos. Chem. Phys. 16, 1161-1186 (2016).

6. C. D. O'Dowd et al., Marine aerosol formation from biogenic iodine emissions. Nature 417, 632-636 (2002).

7. M. Sipilä et al., Molecular-scale evidence of aerosol particle formation via sequential addition of $\mathrm{HIO}_{3}$. Nature 537, 532-534 (2016).

8. R. Volkamer et al., Aircraft measurements of $\mathrm{BrO}, 1 \mathrm{O}$, glyoxal, $\mathrm{NO}_{2}, \mathrm{H}_{2} \mathrm{O}, \mathrm{O}_{2}-\mathrm{O}_{2}$ and aerosol extinction profiles in the tropics: Comparison with aircraft-/ship-based in situ and lidar measurements. Atmos. Meas. Tech. 8, 2121-2148 (2015).

9. S. Wang et al., Active and widespread halogen chemistry in the tropical and subtropical free troposphere. Proc. Natl. Acad. Sci. U.S.A. 112, 9281-9286 (2015).

10. T. M. Sherwen et al., Global impacts of tropospheric halogens $(\mathrm{Cl}, \mathrm{Br}, \mathrm{I})$ on oxidants and composition in GEOS-Chem. Atmos. Chem. Phys. 16, 12239-12271 (2016). of Colorado Boulder $(9,28)$, with extended iodine chemistry $(4)$ including photolysis frequencies measured by HARP (58).

$\mathrm{I}_{\mathrm{y} \text {,part }}$ was measured by the CU HR-AMS $(59,60)$, deployed aboard the National Aeronautics and Space Administration (NASA) DC-8 for all four ATom missions. The DC- 8 aircraft achieved substantial global coverage by flying four circuits over the Pacific and Atlantic oceans in different seasons. ATom-1 flights were conducted in July and August 2016, and ATom-2 flights in January and February 2017, with frequent, unbiased profiling $\left(0\right.$ to $12.5 \mathrm{~km}$ ) of the tropical, midlatitude, and polar atmosphere $\left(67^{\circ} \mathrm{S}\right.$ to $\left.80^{\circ} \mathrm{N}\right)$.

CAM-Chem (version 4) (51) was used to estimate ozone loss rates and the iodine $\left(I_{y}\right)$ budget. Sensitivity studies were conducted examining the effect of excluding: organic sources of iodine and inorganic sources of iodine. Model cases examining the recycling of iodine to the gas phase on different atmospheric surfaces are the same as in ref. 20. CAM-Chem only represents gas-phase iodine chemistry, and the heterogeneous conversion among $\mathrm{I}_{\mathrm{y}}$ gas species. It does not track $\mathrm{I}_{\mathrm{y} \text {, part }}$ or treat chemical reactions in particles. The phase partitioning of iodine is instead based on empirical exponential fits of $\mathrm{I}_{\mathrm{y}, \text { gas }}$ and $\mathrm{I}_{\mathrm{y}, \text { part }}$ inferred from observations against $\mathrm{H}_{2} \mathrm{O} / \mathrm{O}_{3}$ (SI Appendix, Fig. S4 and Eqs. S2, S4, and S5). The ozone destruction by $\mathrm{I}_{\mathrm{y}, \mathrm{part}}$ is calculated as ozone reactive uptake

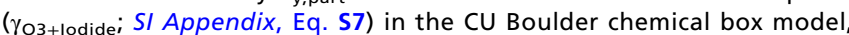
constrained by measured aerosol surface area and chemical and meteorological parameters. The box model is also used to determine the relative efficiencies of $\mathrm{I}_{\mathrm{y}}$ gas and $\mathrm{I}_{\mathrm{y} \text {,part }}$ at destroying ozone (SI Appendix, Fig. S8 and Eq. S8). To compare the odd-oxygen destruction from iodine with other reaction cycles $\left(\mathrm{HO}_{x}\right.$, halogens, $\left.\mathrm{NO}_{x}, \mathrm{O}_{x}\right)$ the $\mathrm{CAM}-\mathrm{Chem}$ gas-phase ozone destruction rate by iodine is adjusted for total $\mathrm{I}_{\mathrm{y}}$ injection, phase partitioning, and the mass weighted ozone destruction efficiencies of $\mathrm{I}_{\mathrm{y} \text {,gas }}$ and $\mathrm{I}_{\mathrm{y} \text {,part }}$ as calculated from the box model, and is described further in SI Appendix.

Data and Materials Availability. The TORERO data is available at https://data eol.ucar.edu/master_lists/generated/torero/, and CONTRAST data at https:// data.eol.ucar.edu/master lists/generated/contrast/. The ATom data is available at https://daac.ornl.gov/cgi-bin/dsviewer.pl?ds_id=1581. CAM-Chem model data are available at https://saco.csic.es/index.php/s/6BkS3PLHYwBKH4g.

ACKNOWLEDGMENTS. We thank the TORERO, CONTRAST, and ATom science teams, particularly D. C. Anderson, E. C. Apel, E. L. Atlas, N. J. Blake, C. A. Brock, T. Campos, D. A. Day, G. S. Diskin, V. Donets, F. M. Flocke, K. Froyd, R. S. Gao, T. F. Hanisco, R. Hornbrook, J. B. Jensen, L. Kaser, A. Kupc, R. Lueb, D. D. Montzka D. Murphy, M. A. Navarro, L. L. Pan, D. J. Price, J. M. Reeves, D. Riemer, T. Ryerson, R. J. Salawitch, S. M. Schauffler, J. C. Schroder, A Weinheimer C. Williamson, S. C. Wofsy, G. M. Wolfe, and M. A. Zondlo. The GV aircraft was operated by the NCAR's Earth Observing Laboratory's (EOL) Research Aviation Facility. The involvement of the NSF-sponsored Lower Atmospheric Observing Facilities, managed and operated by NCAR/EOL, is acknowledged. R.V. and T.K.K. are grateful to Rolf Sanders for helpful discussions. R.V. acknowledges funding by NSF Awards AGS-1104104 (TORERO), AGS-1261740 (CONTRAST) and AGS-1620530. ATom-1 and 2 were supported by NASA's Earth Sys tem Science Pathfinder Program EVS-2 funding (Grants NNX15AH33A, NNX15AJ23G, and 80NSSC19K0124). This study has received funding from the European Research Council Executive Agency under the European Union's Horizon 2020 Research and Innovation Programme (Project ERC2016-COG 726349 CLIMAHAL).

11. T. Sherwen, M. J. Evans, L. J. Carpenter, J. A. Schmidt, L. J. Mickley, Halogen chemistry reduces tropospheric $\mathrm{O}_{3}$ radiative forcing. Atmos. Chem. Phys. 17, 15571569 (2017).

12. A. Saiz-Lopez et al., Estimating the climate significance of halogen-driven ozone loss in the tropical marine troposphere. Atmos. Chem. Phys. 12, 3939-3949 (2012).

13. G. Myhre et al., "Anthropogenic and natural radiative forcing" in Climate Change 2013: The Physical Science Basis. Contribution of Working Group I to the Fifth Assessment Report of the Intergovernmental Panel on Climate Change, T. F. Stocker et al., Eds. (Cambridge University Press, 2013), pp. 659-740

14. L. J. Carpenter et al., "Ozone-depleting substances (ODSs) and other gases of interest to the Montreal Protocol" in Scientific Assessment of Ozone Depletion: 2014, Global Ozone Research and Monitoring Project, A. Engel, S. A. Montzka, Eds. (Report no. 55 World Meteorological Organization, Geneva, Switzerland, 2014).

15. A. Engel et al., "Update on ozone-depleting substances (ODSs) and other gases of interest to the Montreal Protocol" in Scientific Assessment of Ozone Depletion: 2018, Global Ozone Research and Monitoring Project, Q. Liang, S. Reimann, Eds. (Report no. 58, World Meteorological Organization, Geneva, Switzerland, 2018).

16. P. O. Wennberg, J. W. Brault, T. F. Hanisco, R. J. Salawitch, G. H. Mount, The atmospheric column abundance of IO: Implications for stratospheric ozone. J. Geophys. Res. Atmos. 102, 8887-8898 (1997). 
17. I. Pundt, J.-P. Pommereau, C. Phillips, E. Lateltin, Upper limit of iodine oxide in the lower stratosphere. J. Atmos. Chem. 30, 173-185 (1998).

18. H. Bösch et al., Upper limits of stratospheric $1 \mathrm{O}$ and OIO inferred from center-to-limbdarkening-corrected balloon-borne solar occultation visible spectra: Implications for total gaseous iodine and stratospheric ozone. J. Geophys. Res. 108, 4455 (2003).

19. A. Butz et al., Constraints on inorganic gaseous iodine in the tropical upper troposphere and stratosphere inferred from balloon-borne solar occultation observations. Atmos. Chem. Phys. 9, 7229-7242 (2009).

20. A. Saiz-Lopez et al., Injection of iodine to the stratosphere. Geophys. Res. Lett. 42 6852-6859 (2015)

21. D. M. Murphy et al., In situ measurements of organics, meteoritic material, mercury, and other elements in aerosols at 5 to 19 kilometers. Science 282, 1664-1669 (1998).

22. D. M. Murphy, K. D. Froyd, J. P. Schwarz, J. C. Wilson, Observations of the chemical composition of stratospheric aerosol particles. Q. J. R. Meteorol. Soc. 140, 1269-1278 (2014).

23. L. L. Pan et al., The convective transport of active species in the tropics (CONTRAST) experiment. Bull. Am. Meteorol. Soc. 98, 106-128 (2017)

24. R. Volkamer, T. K. Koenig, B. Dix, S. Baidar, CONTRAST: Airborne multi-axis differential optical absorption spectroscopy (AMAX-DOAS) data. NCAR EOL. https://data. eol.ucar.edu/dataset/383.023 Deposited 20 December 2019

25. B. Dix, T. K. Koenig, R. Volkamer, Parameterization retrieval of trace gas volume mixing ratios from Airborne MAX-DOAS. Atmos. Meas. Tech. 9, 5655-5675 (2016)

26. S. C. Wofsy et al., ATom: Merged Atmospheric Chemistry, Trace Gases, and Aerosols (Oak Ridge National Laboratory Distributed Active Archive Center, 2018)

27. J. L. Jimenez, P. Campuzano-Jost, D. A. Day, B. A. Nault, J. C. Schroder, Particulat iodine concentrations and associated ion fractions for ATom-1 and ATom-2. Open Science Framework. https://doi.org/10.17605/OSF.IO/VR6NB. Deposited 30 December 2019.

28. T. K. Koenig et al., BrO and $\mathrm{Br}_{\mathrm{y}}$ profiles over the Western Pacific: Relevance of inorganic bromine sources and a $\mathrm{Br}_{\mathrm{y}}$ minimum in the aged tropical tropopause layer. Atmos. Chem. Phys. 17, 15245-15270 (2017)

29. A. Saiz-Lopez, R. P. Fernandez, On the formation of tropical rings of atomic halogens: Causes and implications. Geophys. Res. Lett. 43, 2928-2935 (2016).

30. L. Magi et al., Investigation of the uptake rate of ozone and methyl hydroperoxide by water surfaces. J. Phys. Chem. A 101, $4943-4949$ (1997)

31. A. Rouvière, Y. Sosedova, M. Ammann, Uptake of ozone to deliquesced $\mathrm{KI}$ and mixed $\mathrm{KI} / \mathrm{NaCl}$ aerosol particles. J. Phys. Chem. A 114, 7085-7093 (2010).

32. E. A. Pillar, M. I. Guzman, J. M. Rodriguez, Conversion of iodide to hypoiodous acid and iodine in aqueous microdroplets exposed to ozone. Environ. Sci. Technol. 47, 10971-10979 (2013)

33. L. J. Carpenter et al., Atmospheric iodine levels influenced by sea surface emissions of inorganic iodine. Nat. Geosci. 6, 108-111 (2013).

34. S. Dushman, The rate of the reaction between iodic and hydriodic acids. J. Phys. Chem. 8, 453-482 (1903)

35. W. C. Bray, H. A. Liebhafsky, Reactions involving hydrogen peroxide, iodine and iodate ion. I. Introduction. J. Am. Chem. Soc. 53, 38-44 (1931).

36. K. S. Law et al., "Halogenated Very Short-Lived Substances" in Scientific Assessment of Ozone Depletion: 2006, Global Ozone Research and Monitoring Project-Report No. 50 (World Meteorological Organization, 2006)

37. W. T. Ball et al., Evidence for a continuous decline in lower stratospheric ozone offsetting ozone layer recovery. Atmos. Chem. Phys. 18, 1379-1394 (2018).

38. C. A. Cuevas et al., Rapid increase in atmospheric iodine levels in the North Atlantic since the mid-20th century. Nat. Commun. 9, 1452 (2018)
39. M. Legrand et al., Alpine ice evidence of a three-fold increase in atmospheric iodine deposition since 1950 in Europe due to increasing oceanic emissions. Proc. Natl. Acad. Sci. U.S.A. 115, 12136-12141 (2018).

40. X. Zhao, X. Hou, W. Zhou, Atmospheric iodine $\left({ }^{127} \mathrm{I}\right.$ and $\left.{ }^{129} \mathrm{I}\right)$ record in spruce tree rings in the northeast Qinghai-Tibet Plateau. Environ. Sci. Technol. 53, 8706-8714 (2019).

41. J. B. Burkholder, R. A. Cox, A. R. Ravishankara, Atmospheric degradation of ozone depleting substances, their substitutes, and related species. Chem. Rev. 115, 37043759 (2015).

42. E. Rischbieter, H. Stein, A. Schumpe, Ozone solubilities in water and aqueous salt solutions. J. Chem. Eng. Data 45, 338-340 (2000).

43. S. Weisenberger, A. Schumpe, Estimation of gas solubilities in salt solutions at temperatures from $273 \mathrm{~K}$ to $363 \mathrm{~K}$. AlChE J. 42, 298-300 (1996).

44. A. V. Harcourt, On the observation of the course of chemical change. J. Chem. Soc. 20, 460-492 (1867)

45. H. Landolt, Ueber die Zeitdauer der Reaction zwischen Jodsäure und schwefliger Säure. Ber. Dtsch. Chem. Ges. 19, 1317-1365 (1886)

46. L. Treindl, R. M. Noyes, A new explanation of the oscillations in the Bray-Liebhafsky reaction. J. Phys. Chem. 97, 11354-11362 (1993).

47. R. Vogt, R. Sander, R. Von Glasow, P. J. Crutzen, lodine chemistry and its role in halogen activation and ozone loss in the marine boundary layer: A model study. J. Atmos. Chem. 32, 375-395 (1999).

48. G. Schmitz, Z. Noszticzius, G. Hollo, M. Wittmann, S. D. Furrow, Reactions of iodate with iodine in concentrated sulfuric acid. Formation of $\mathrm{I}(+3)$ and $\mathrm{I}(+1)$ compounds. Chem. Phys. Lett. 691, 44-50 (2018).

49. C. Prados-Roman et al., A negative feedback between anthropogenic ozone pollution and enhanced ocean emissions of iodine. Atmos. Chem. Phys. 15, 2215-2224 (2015).

50. A. Saiz-Lopez, C. A. Cuevas, R. P. Fernandez, D. Kinnison, CAM-Chem output data for quantitative detection of iodine in the stratosphere. AC2-CSIC. http://saco.csic.es/index. $\mathrm{php} / \mathrm{s} / 6 \mathrm{BkS3PLHYwBKH4g}$. Deposited 20 December 2019.

51. J.-F. Lamarque et al., CAM-Chem: Description and evaluation of interactive atmospheric chemistry in the community earth system model. Geosci. Model Dev. 5, 369411 (2012).

52. M. P. Chipperfield et al., On the cause of recent variations in lower stratospheric ozone. Geophys. Res. Lett. 45, 5718-5726 (2018).

53. O. Gálvez, J. C. Gómez Martín, P. C. Gómez, A. Saiz-Lopez, L. F. Pacios, A theoretical study on the formation of iodine oxide aggregates and monohydrates. Phys. Chem. Chem. Phys. 15, 15572-15583 (2013).

54. A. E. Dessler et al., Transport of ice into the stratosphere and the humidification of the stratosphere over the 21st century. Geophys. Res. Lett. 43, 2323-2329 (2016).

55. J. G. Anderson, C. E. Clapp, Coupling free radical catalysis, climate change, and human health. Phys. Chem. Chem. Phys. 20, 10569-10587 (2018)

56. L. J. Mickley et al., Radiative forcing from tropospheric ozone calculated with a unified chemistry-climate model. J. Geophys. Res. Atmos. 104, 30153-30172 (1999).

57. P. J. Nowack et al., A large ozone-circulation feedback and its implications for global warming assessments. Nat. Clim. Chang. 5, 41-45 (2015).

58. R. E. Shetter, M. Müller, Photolysis frequency measurements using actinic flux spectroradiometry during the PEM-Tropics mission: Instrumentation description and some results. J. Geophys. Res. Atmos. 104, 5647-5661 (1999)

59. J. C. Schroder et al., Sources and secondary production of organic aerosols in the northeastern United States during WINTER. J. Geophys. Res. Atmos. 123, 7771-7796 (2018)

60. B. A. Nault et al., Secondary organic aerosol production from local emissions dominates the organic aerosol budget over Seoul, South Korea, during KORUS-AQ. Atmos. Chem. Phys. 18, 17769-17800 (2018). 